\title{
Hypertension and diabetes-related morbidity and mortality trends in a municipality in the countryside of São Paulo ${ }^{1}$
}

\author{
Andreia Francesli Negri Reis ${ }^{2}$ \\ Juliana Cristina Lima ${ }^{3}$ \\ Lucia Marinilza Beccaria ${ }^{4}$ \\ Rita de Cassia Helú Mendonça Ribeiro ${ }^{4}$ \\ Daniele Favaro Ribeiro ${ }^{5}$ \\ Claudia Bernardi Cesarino ${ }^{4}$
}

Objectives: to identify the main causes for hospital admissions and deaths related to systemic arterial hypertension and diabetes mellitus (DM), and to analyze morbidity and mortality trends, in a municipality in São Paulo's countryside, by comparing two three-years periods, 2002 to 2004 and 2010 to 2012. Methods: cross-sectional study which used secondary data regarding deaths from the Information System on Mortality and concerning hospital admissions from the DataSus Hospital Information System. Univariate and multivariate statistical analyses were conducted. Results: from 2002 to 2012, 325,439 people were admitted to hospitals, $14.7 \%$ of them due to circulatory system diseases (CSD) and 0.7\% due to DM. The deaths distributed as the following: 29,027 deaths (31.5\%) were due to CSD; $8.06 \%$ due to cerebrovascular diseases (CVD); and $2.75 \%$ due to DM. There was a significant association between admittance and death causes and patients' gender and age in the three-year periods $(p<0.001)$. The highest lethality in hospital admissions was found to be due to CVD (10\%). That trend showed that mortality rates dropped, younger patients were admitted due to DM, and older patients were admitted due to CVD - they were more often females. Conclusion: the main causes for hospital admissions were the CSDs; main mortality causes were the CVDs in hypertensive and diabetic women. Those findings can back public policies which prioritize the promotion of health.

Descriptors: Mortality; Hospitalization; Cardiovascular Diseases; Diabetes Mellitus.

\footnotetext{
1 Paper extracted from master's thesis "Epidemiology of hypertension and diabetes in São José do Rio Preto, 2002-2012", presented to Faculdade de Medicina de São José do Rio Preto, São José do Rio Preto, SP, Brazil.

2 Master's student, Faculdade de Medicina de São José do Rio Preto, São José do Rio Preto, SP, Brazil. RN, Secretaria Municipal de Saúde, São José do Rio Preto, SP, Brazil.

3 Undergraduate student in Nursing, Faculdade de Medicina de São José do Rio Preto, São José do Rio Preto, SP, Brazil. Scholarship holder from Conselho Nacional de Desenvolvimento Científico e Tecnológico (CNPq), Brazil.

${ }_{4}^{4}$ PhD, Professor, Faculdade de Medicina de São José do Rio Preto, São José do Rio Preto, SP, Brazil.

5 Doctoral student, Faculdade de Medicina de São José do Rio Preto, São José do Rio Preto, SP, Brazil. RN, Hospital de Base de São José do Rio Preto, São José do Rio Preto, SP, Brazil. Scholarship holder from Coordenação de Aperfeiçoamento de Pessoal de Nível Superior (CAPES), Brazil.
}

Corresponding Author:

Claudia Bernardi Cesarino

Faculdade de Medicina de São José do Rio Preto

Av. Brigadeiro Faria Lima, 5416

Bairro: São Pedro

CEP: 15092-530, São José do Rio Preto, SP, Brasi

E-mail: claudiacesarino@famerp.br
Copyright (c) 2015 Revista Latino-Americana de Enfermagem This is an Open Access article distributed under the terms of the Creative Commons Attribution Non-Commercial License (CC BY-NC).

This license lets others distribute, remix, tweak, and build upon your work non-commercially, and although their new works must also acknowledge you and be non-commercial, they don't have to license their derivative works on the same terms. 


\section{Introduction}

Most non-communicable diseases (NCDs) are some of the main public health problems, and they have been known worldwide to be the main causes for deaths and hospital admissions for decades. Those diseases play an important role regarding the number of disabilityadjusted life years (DALY - life years that are lost due to early death or disability). A study that was based on that index found NCDs to account for $41.0 \%$ of the total DALY number worldwide. In 1990 and in 2020, they will respectively account for up to $73.0 \%$ and $60.0 \%$ of total deaths and DALY, worldwide(1).

Systemic arterial hypertension (SAH) and diabetes mellitus (DM) are included in the NCDs, accounting for the main death causes all over Brazil. Those are clinical conditions with an important social impact, considering their multiple risk factor, thus being seen as health problems that should be prioritized by society, due to the high numbers of hospital admissions and deaths they are responsible for ${ }^{(1-2)}$.

In the United States, current information indicates the possibility for a new epidemiological transition to be in course. As in Brazil, increased prevalence of risk factors is observed, unlike previous decades, as well as trend for increased mortality in the young adult range, between 35 and 44 years of age ${ }^{(3)}$.

In Brazil, over the last few decades, trends for general mortality and mortality due to circulatory system diseases (CSD) have been observed to be reduced. However, they are still the main causes of death ${ }^{(4)}$. In São José do Rio Preto, as of 1985, mortality rates have been observed to be similar to the ones regarding Brazil as a whole ${ }^{(5)}$. The main reason for reduced CSD mortality worldwide refers to controlling its risk factors, and that is followed by advances in CSD treatment ${ }^{(4)}$.

According Vigitel study, by the Ministry of Health, SAH and DM have acute myocardial infarction, cerebrovascular accidents, chronic kidney failure, heart failure, limb amputations, definitive blindness, and others, as their most prevalent complications ${ }^{(6)}$.

Standard knowledge on the patterns for hospital morbidity in Brazilian Unified Health Care System (SUS) services and on mortality due to all CSDs and DM may back the creation of measures for decision-making in actions aiming to inform on, prevent, and control chronic diseases. Thus, this study intended to identify the main causes for hospital admissions and deaths related to systemic arterial hypertension and diabetes mellitus (DM), and to analyze morbidity and mortality trends, in a municipality in São Paulo's countryside, by comparing two three-year periods, 2002 to 2004 and 2010 to 2012, in São José do Rio Preto.

\section{Method}

This is a descriptive, cross-sectional study that was developed in São José do Rio Preto's health protection agency, in São Paulo state. Secondary data regarding deaths of residents from São José do Rio Preto were collected from the Information System on Mortality (SIM) and the ones concerning hospital admissions were collected from DataSus' website Hospital Information System (SIH), regarding the period between 2002 and 2012. This study is part of more comprehensive research named "Epidemiologia da hipertensão e diabetes em São José do Rio Preto de 2002 a 2012" (Epidemiology of hypertension and diabetes in São José do Rio Preto from 2002 to 2012) - this period was selected according to opening and closing-cycle dates of Recording and Supervision System for Hypertensive and Diabetic Patients (Hiperdia) from the Ministry of Health. Morbidity and mortality trends were analyzed by having three-year periods from Hiperdia compared - 2002 to 2004 (start) and 2010 to 2012 (end).

The data were analyzed according to the set of circulatory system diseases and the codes regarding diseases in the International Statistical Classification of Diseases and Related Health Problems, 10th Revision (ICD10), according to its morbidity list: complications from diabetes mellitus, E10 to E14; and arterial hypertension: the circulatory system diseases (CSDs) among these, especially, ischemic heart disease (IHD), I20 to I25; and cerebrovascular diseases (CVD), I60 to I69.

Aiming to estimate risk of death due to IHD, CVD, and DM, the crude mortality rate (CMR) per 100,000 inhabitants was calculated. As CMR is influenced by the effects from different age structures as years go by, the data were submitted to direct standardization, in order to check whether expected deaths outnumbered the rates which were observed in the periods. The population estimates and data from 2010 census were obtained from information from IBGE (Brazilian Institute of Geography and Statistics), which were available on DataSus' website $^{(7)}$.

The statistical study was divided in two steps: the first one was the study on patient admissions and their causes, evaluating the influence of variables such as gender, age, and lethality. The second step consisted of 
the analysis of deaths in the municipality, by comparing the related periods, in order to analyze trend behaviors of causes for hospital admissions and deaths in those periods.

The data were analyzed according to three approaches: an associative approach of qualitative variables (cases for admissions and deaths related to gender and lethality) through the application of chi squared test; a comparative approach in order to check for age differences regarding admission and death causes through the application of Variance analysis (ANOVA); and an age progression approach in the three-year periods, by restricting admission and death causes through the application of student's t test for independent samples and multivariate analysis, in order to relate all analyzed variables to the evaluated three-year periods. Multiple Correspondence Analysis (MCA) is based on a set of variables which collectively guide the analysis and behavior of the relationships among evaluated variables. In this case, fiver variables were evaluated, which added up to 18 levels. These levels are arranged according to higher or lower interaction levels among variables, showing their relationships in a two-dimensional space. That makes statistical analyses easier and finds results which would not normally be found by univariate analyses. Thus, MCA is a key tool for finding relationships among classified variables, in order to indicate the behaviors of the variables which were evaluated in this study, and to avoid certain kinds of bias.

The data were organized in an Excel spreadsheet. A significance level of $p<0.05$ was adopted for the statistical analysis. Minitab 17 and Statistica 10 were the softwares used. The project was approved by the Research Ethics Committee of São José do Rio Preto Medical School, under CAAE protocol no. 05855012.5.0000.5415/2012.

\section{Results}

In São José do Rio Preto, from 2002 to 2012, 325,439 hospital admissions were recorded, $14.7 \%$ of which due to CSD and $0.7 \%$ due to DM. 29,027 deaths were recorded, $31.5 \%$ of which being attributed to CSD, and $2.75 \%$ to DM. The data were analyzed with all records from SIH and SIM, including poorly-defined causes, which made up for $0.08 \%$ of the total.

It should be mentioned that population patterns in the three-year periods in the study was not found to be significantly altered in regards to gender and age range. The female populations, as estimated by IBGE, accounted for $51.61 \%$ and $51.99 \%$, respectively.

Average inpatient age in the period from 2002 to 2004 was $59.00 \pm 16.86$ years, and that was similar to the period from 2010 to 2012, with an average age of $59.31 \pm 16.59$ years.

Gender and age were observed to significantly influence $(p<0.001)$ the cause for hospital admissions. Most hospital admissions due to diabetes ( $>50.22 \%$ ), CVD (>53.59\%), and IHD ( $<55.78 \%)$ were of female patients, and hospital admissions due to other circulatory causes ( $>52.77 \%$ ) were of male patients for both threeyear periods.

In the two studied periods, causes for hospital admissions were significantly associated to lethality, which accounted for $5.35 \%$ of inpatient deaths and had significant rates for CVD-related deaths - above $10.00 \%$ in both periods.

Table 1 shows that age significantly influenced the hospital admission causes in both periods. In the comparative approach, diabetes patients were found to be younger as compared to the remaining patients, and CVD patients were found to be older as compared to patients who were admitted for other causes. This result was repeated in both three-year periods. CVD $(p<0.001)$ and IHD-related admission ages increased throughout the three-year periods.

Table 1 - Distribution of causes for hospital admissions due to diabetes mellitus, cerebrovascular diseases, ischemic heart disease, and other circulatory system diseases, and related average ages in two three-year periods, from 2002 to 2004 and from 2010 to 2012. São José do Rio Preto, SP, Brazil

\begin{tabular}{|c|c|c|c|c|c|}
\hline \multirow{2}{*}{$\begin{array}{l}\text { Hospital } \\
\text { admission } \\
\text { causes }\end{array}$} & \multicolumn{2}{|c|}{2002 to 2004} & \multicolumn{2}{|c|}{2010 to 2012} & \multirow{2}{*}{$\begin{array}{c}p \\
\text { value }^{\dagger}\end{array}$} \\
\hline & $\mathbf{n}$ & Average $\pm S D^{*}$ & $\mathbf{n}$ & Average $\pm S D^{*}$ & \\
\hline $\begin{array}{l}\text { Diabetes } \\
\text { mellitus }\end{array}$ & 462 & $54.25 \pm 19.21$ & 524 & $53.90 \pm 20.69$ & 0.783 \\
\hline $\begin{array}{l}\text { Cerebrovascular } \\
\text { diseases }\end{array}$ & 1680 & $61.80 \pm 16.39$ & 1836 & $64.30 \pm 15.74$ & $<0.001$ \\
\hline $\begin{array}{l}\text { Ischemic heart } \\
\text { disease }\end{array}$ & 3702 & $60.32 \pm 12.62$ & 4454 & $61.02 \pm 12.41$ & 0.012 \\
\hline $\begin{array}{l}\text { Other circulatory } \\
\text { system diseases }\end{array}$ & 6134 & $57.79 \pm 18.75$ & 7026 & $57.34 \pm 18.26$ & 0.163 \\
\hline$p$ value ${ }^{\ddagger}$ & & $<0.001$ & & $<0.001$ & \\
\hline
\end{tabular}

\footnotetext{
* Standard Deviation

+ Student's t test

₹ Variance Analysis (ANOVA)
}

Through MCA, it is possible to observe in Figure 1 that the following variables were evaluated: threeyear period, age (classified as age ranges), gender, 
admission causes, and lethality. In quadrants 1 and 2 , the analysis results regarding the threeyear periods can be found. They do not differ significantly, as they are located close to each other and to the origin in the chart. In quadrant 2, dead inpatients were found to be 70 years or older, and their main cause for admission was CVD. Quadrant 3 shows that patients who were admitted due to diabetes or other CSDs are males who are younger than 39 years old. In quadrant 4, IHD inpatients are observed to generally be females of ages between 50 and 69 years.

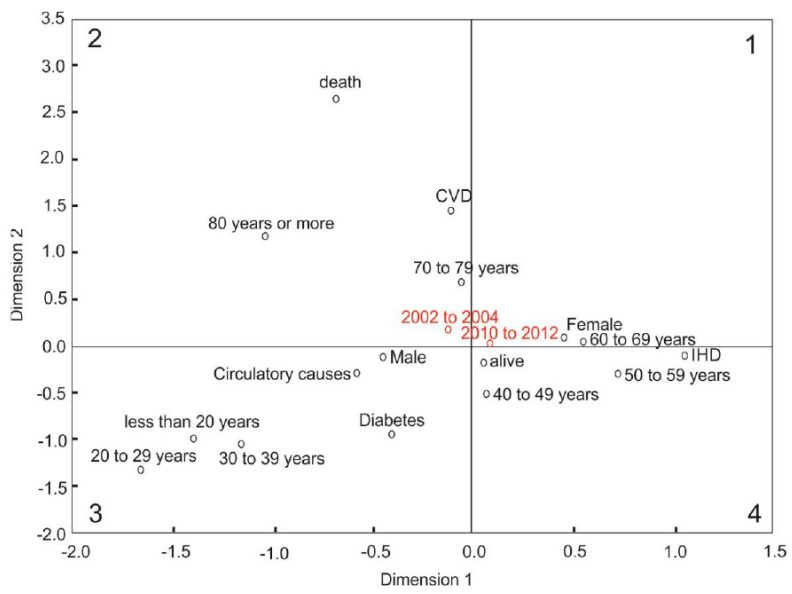

Figure 1 - Distribution of causes for hospital admissions: diabetes, cerebrovascular diseases (CVDs), ischemic heart diseases (IHD), and circulatory causes, according to age ranges, genders, lethality in São José do Rio Preto, SP state, three-year periods from 2002 to 2004 and from 2010 to 2012.

Table 2 shows the percentages of studied variables regarding deaths recorded on SIM, as divided in the three-year periods in the study. The average ages of dead patients due to the studied causes in both three-year periods were $70.83 \pm 14.32$ years and $71.97 \pm 14.26$ years, respectively. CMRs showed increased mortality rates due to the specific causes from a three-year period to another. However, for comparison purposes, the standardized mortality coefficients (SMC) showed that mortality rates due to specific DM, CVD, and IHD causes were found to drop throughout the three-year periods, whereas the other CSDs were found to have greater coefficients when three-year periods are compared.
Table 2 - Distribution, crude mortality and standardized death coefficients, according to its causes and patient genders in three-year periods from 2002 to 2004 and from 2010 to 2012, São José do Rio Preto, Brazil.

\begin{tabular}{|c|c|c|c|c|c|}
\hline $\begin{array}{l}\text { Three-year } \\
\text { period }\end{array}$ & Death variables & n & $\%$ & $\mathrm{CMR}^{*}$ & $\mathrm{SMC}^{\dagger}$ \\
\hline \multirow[t]{8}{*}{2002 to 2004} & Gender & 2533 & 100 & & \\
\hline & Feminine & 1218 & 48.09 & 205.78 & - \\
\hline & Masculine & 1315 & 51.91 & 236.98 & - \\
\hline & Death cause & 2533 & 100 & & \\
\hline & Diabetes mellitus & 201 & 7.94 & 17.53 & 21.12 \\
\hline & $\begin{array}{l}\text { Cerebrovascular } \\
\text { diseases }\end{array}$ & 613 & 24.20 & 53.45 & 64.93 \\
\hline & $\begin{array}{l}\text { Ischemic heart } \\
\text { diseases }\end{array}$ & 869 & 34.31 & 75.78 & 91.38 \\
\hline & $\begin{array}{l}\text { Other circulatory } \\
\text { causes }\end{array}$ & 850 & 33.56 & 74.11 & 90.37 \\
\hline \multirow[t]{8}{*}{2010 to 2012} & Gender & 2837 & 100 & 229.51 & \\
\hline & Feminine & 1405 & 49.52 & 218.64 & - \\
\hline & Masculine & 1432 & 50.48 & 241.29 & - \\
\hline & Death cause & 2837 & 100 & & \\
\hline & Diabetes mellitus & 239 & 8.42 & 19.33 & 17.47 \\
\hline & $\begin{array}{l}\text { Cerebrovascular } \\
\text { diseases }\end{array}$ & 657 & 23.16 & 53.15 & 47.87 \\
\hline & $\begin{array}{l}\text { Ischemic heart } \\
\text { diseases }\end{array}$ & 893 & 31.48 & 72.24 & 65.50 \\
\hline & $\begin{array}{l}\text { Other circulatory } \\
\text { causes }\end{array}$ & 1048 & 36.94 & 84.78 & 76.46 \\
\hline
\end{tabular}

* Crude mortality rate per 100,000 inhabitants, through the addition of total and proportional populations per gender, regarding three-year periods from 2002 to 2004 and from 2010 to 2012.

† Directly standardized mortality coefficient (the sum of deaths and populations regarding both three-year periods). São José do Rio Preto's standard 2007 population was used.

A statistically significant association was found between death causes and patients' genders and ages. Mortality was found to higher for women regarding diabetes and other CSDs for both threeyear periods. Men died more frequently of ischemic heart diseases (IHDs). Regarding CVD-related deaths $(51.71 \%)$, men were more affected in the period from 2002 to 2004. However, from 2010 to 2012 the situation was the opposite; that is, more women died of CVDs (50.99\%).

According to Table 3, from 2002 to 2004 $(p=0.029)$, IHD patients were observed to die at younger ages as compared to patients who died of other CSDs. In turn, from 2010 to $2012(p=0.008)$, there was a significant difference between patients who died of CVD and IHD, and patients who died of CVD were found to be older in average as compared to patients who died from IHD. 
Table 3 - Distribution of admission causes and average ages, according to periods from 2002 to 2004 and from 2010 to 2012, São José do Rio Preto, SP, Brazil

\begin{tabular}{|c|c|c|c|c|c|}
\hline \multirow{2}{*}{ Death cause } & \multicolumn{2}{|c|}{2002 to 2004} & \multicolumn{2}{|c|}{2010 to 2012} & \multirow{2}{*}{$\stackrel{p}{\text { value }^{\dagger}}$} \\
\hline & $\mathbf{n}$ & Average $\pm S D^{*}$ & $\mathbf{n}$ & Average $\pm S D^{*}$ & \\
\hline $\begin{array}{l}\text { Diabetes } \\
\text { mellitus }\end{array}$ & 201 & $70.13 \pm 13.62$ & 239 & $71.63 \pm 13.74$ & 0.252 \\
\hline $\begin{array}{l}\text { Cerebrovascular } \\
\text { diseases }\end{array}$ & 613 & $70.79 \pm 14.46$ & 657 & $73.44 \pm 13.42$ & 0.001 \\
\hline $\begin{array}{l}\text { Ischemic heart } \\
\text { diseases }\end{array}$ & 869 & $69.94 \pm 13.54$ & 893 & $70.92 \pm 13.34$ & 0.125 \\
\hline $\begin{array}{l}\text { Other } \\
\text { circulatory } \\
\text { causes }\end{array}$ & 850 & $71.95 \pm 15.08$ & 1048 & $72.04 \pm 15.52$ & 0.901 \\
\hline$p$ value ${ }^{\ddagger}$ & & 0.029 & & 0.008 & \\
\hline
\end{tabular}

* Standard deviation

+ Student's t test

\# Variance Analysis (ANOVA)

Figure 2 shows the Multiple Correspondence Analysis, as divided in four quadrants, showing that mortality rates are not different in quadrants 1 and 2 between evaluated periods, as those periods were located close to one another and to the origin of the chart. Also in quadrant 1 , it is possible to observe that IHD-related mortality predominated in the age range between 40 and 69 years and in the male gender. In quadrant 2, patients who died of CVD and diabetes were found to generally be females older than 70 years. Quadrants 3 and 4 show that patients younger than 39 years were not found to have high death frequencies regarding studied causes, as such patients were located far from the evaluated diseases and to have low diabetes-related death frequencies.

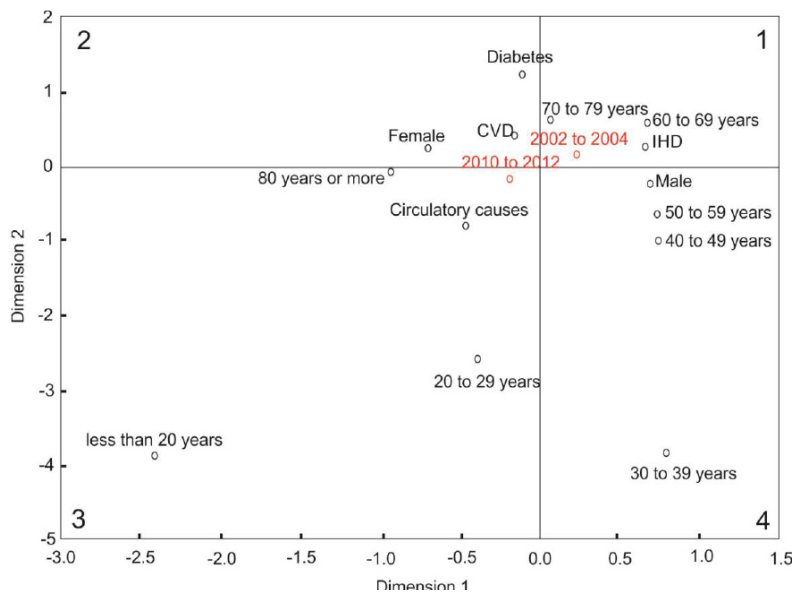

Figure 2 - Distribution of deaths caused by diabetes, cerebrovascular diseases (CVDs), ischemic heart diseases (IHDs), and circulatory causes, according to age ranges and genders, São José do Rio Preto, SP, Brazil, periods from 2002 to 2004 and from 2010 to 2012

\section{Discussion}

This study found that the average ages for admission of CSD and DM patients were, respectively, 59 years and 61 years. Their average ages at death were 70 and 71 years. This study compared hospital admissions of young and elderly Brazilian patients to SUS hospitals, and it found that admission rates are higher in extreme age ranges, gradually increasing after age $50^{(8)}$.

In Brazil, the CSDs which are generally associated with $\mathrm{SAH}$ are among the main causes of death, accounting for $7.4 \%$ of total hospital admissions. They lead to high direct and indirect costs. From 2002 to 2012, all CSDs accounted for $14.7 \%$ of total hospital admissions in the municipality; that is, proportionally twice as much as compared to countrywide numbers.

A significant relationship was found between hospital admission and feminine gender for DM, IHD, and CVD. Hospital admissions due to DM and all CSDs are considered by the Ministry of Health as admissions due to critical primary health care conditions, as these deal with a set of health problems for which effective primary health care action would lead to diminished risk of hospital admission ${ }^{(10)}$.

Among the hospital admissions due to studied causes, the other CSDs in male patients were statistically significant. A study between 1998 and 2007 on cardiovascular diseases in Londrina/PR state showed higher admission coefficients for men, for three cause groups: IHD, CVD, and heart failure for most age ranges. CVD-related hospital admission was also found to have significantly increased among men, unlike the findings in this study, which showed that most hospital admissions due to DM, CVD, and IHD regarded female patients $^{(11)}$.

In the United States, a study with sample data found that, between 2001 and 2010, hospital admissions were found to significantly drop in age ranges that were over 55 years or in gender-stratified age ranges. In regards to hospital lethality, it was also found to have significantly dropped for women from 2001 to 2010 (from 3.3\% to $2.3 \%$, a relative variation of $30.5 \%, p<0.0001$ ), but not for men (from $2 \%$ to $1.8 \%$, a relative variation of $8.6 \%$, $\mathrm{p}=0.60)^{(12)}$.

This study results showed that CVDs are found to have higher hospital lethality indices (10\%), as compared to the remaining evaluated diseases. A study that was conducted in Niterói confirms those findings, as it showed increased hospital mortality coefficients due to $\mathrm{CVDS}^{(11)}$. 
The comparison of hospital admissions between the three-year periods found that patient ages influenced and determined admission types. Thus, regarding analyzed causes, younger male patients were admitted due to diabetes; patients between 50 and 69 years were admitted due to IHD, and they were mostly women; and the ones admitted due to CVDs were found to be predominantly female patients of more advanced ages. A study in countryside Paraná state showed that men were more frequently admitted due to CVDs, and were found to be more frequently hospitalized due to IHD and CVDs than women ${ }^{(11)}$.

A study that was conducted between 1950 and 1988, regarding CVD-related mortality trends in Brazil, found proportional increase of CVD-related mortality in all Brazilian capitals - showing that this cause is highlighted in the CSD group. CVDs, among the circulatory causes, are the second most frequent cause of deaths worldwide (5.7 million per year). In 2005, they were responsible for approximately $10 \%$ of all deaths in the world(13-14).

The finding that $31.5 \%$ of deaths that are attributed to circulatory causes in São José do Rio Preto, from 2002 to 2012, corroborated countrywide results, which showed those causes to make up for $31.5 \%$ of total deaths. However, whereas $2.75 \%$ of deaths were observed to be caused by DM in the city, in the country those accounted for $5.2 \%$. Historical series of studied mortality statistics for Brazilian state capitals showed that the share of deaths due to NCDs was found to have increased over three-fold between 1930 and 2006(15).

In regards to mortality, IHDs are observed to be the main death causes among studied diseases, according to a study that was conducted in the metropolitan region of São Paulo and in Niterói (Rio de Janeiro state), which found higher mortality rates due to IHDs than due to CVDs. In the country as whole, however, mortality rates were observed to be more frequently due to CVDs than to $\operatorname{IHDs}^{(16-17)}$. This finding may be justified in the fact that São José do Rio Preto is considered a reference cardiology center. In Western European countries and in the USA, death by IHDs is around three times more frequent than by CVDs, which is not observed in Eastern European, Asian, and Latin American countries. In Brazil, CVDs outrate IHDs, but the trend for reduction of CVDs was higher than the one that was observed for IHDs(16).

Mortality due to studied diseases was found to be significantly associated with genders. Women are found to more frequently die of DM and other CSDs, even though they account for most IHD and CVD-related hospital admissions. Male patients more frequently die of IHDs, and CVD-related deaths were observed to be predominant for males between 2002 and 2004. Those deaths increased in the period from 2010 to 2012 for women. A study that was conducted in Porto Alegre (RS state) found that CVD-related mortality in the 45 to 64-year old population was especially observed among women $^{(18)}$. CVDs were found to affect a higher and rising share of women in São Paulo in another study which evaluated two three-year periods, from 1996 to 1998 (50.9\%) and from 2008 to $2010(53.1 \%)^{(19)}$.

The mortality profile in Brazil differs from the ones in the United States and in some European countries, as it shows a higher number of CVDs as compared to IHDs and early deaths, which are still common in Brazil. The data from the municipality follow the pattern that is observed in the USA and in Europe, in which IDHs predominate ${ }^{(20)}$. In Europe and in the European Union, CSDs are the main death causes (4.30 and 2.0 million deaths, respectively, each year), accounting for $48 \%$ and $42 \%$, respectively ${ }^{(21)}$. In this study, CSDs accounted for $31.5 \%$ of total deaths. In the last three-year period, mortality due to DM, CVD, and other CSDs were observed to increase in a statistically significant way for women, while the same was observed between IHDs and men.

DM causes around $5 \%$ of all deaths worldwide each year. $80 \%$ of people affected by DM are observed to live in underdeveloped or developing countries, to be middle-aged, and not to be elderly. DM-related deaths are estimated to increase by over $50 \%$ in the next 10 years, in case urgent measures are not taken ${ }^{(22)}$. DM in Brazil is found to more frequently affect younger people, as observed in developed countries ${ }^{(23)}$.

This study found that IHDs are the main cause of death in São José do Rio Preto municipality, including in age ranges up to 50 years. Ages are found to significantly increase mortality rates - IHD patients were observed to die at younger ages as compared to patients who died of other CSDs.

The constraints in this study relate to the data that were extracted from databases with information from the Ministry of Health about hospital admissions and deaths. Despite complete data having been found in those information systems, they may contain errors which are related to diagnoses entered in Autorização de Internação Hospitalar (AIH) forms (Hospital Admission Consent Form), as well as to the accuracy of causes that are entered in death certificates and to poorly-defined deaths. In 2012, in Brazil, $6.8 \%$ of total deaths were recorded to have poorly-defined causes. In São José do Rio Preto municipality, in turn, that same indicator was 
$0.88 \%$. Even with that low index, the aforementioned constraints are important, as they are secondary data.

Chronic SAH and DM represent a public health problem, due to the negative impact on the lives of people suffering from those diseases, and in the organization of health care services. SAH and DM are NCDs which progress in a silent fashion - in many cases, throughout the years, if not properly treated or late detected. That leads to serious consequences, increasing hospital admission and mortality rates. Planning nursing care in NCDs is key, through the development of activities regarding health protection, disease prevention, full and longitudinal health care, thus improving the quality of life of the population and attention to those diseases by health care teams ${ }^{(24)}$. Considering that scenario, new approaches in specific NCD education processes must be adopted, in order to help change the local practical reality.

\section{Conclusion}

Nowadays, in Brazil, as in Europe, the United States, and other developed countries, the reduced mortality due to CSDs is evident and consistent, even as the population ages and its life expectancy is extended. The main causes for deaths and hospital admissions are the IHDs, followed by the CVDs. DM-related mortality and hospital admission rates, despite being reduced throughout the years, is still concerning, as it affects younger age ranges, between 20 and 59 years. The identification of morbidity and mortality causes due to $\mathrm{SAH}$ and DM, as well as the association and comparison of general mortality, hospital admissions, and hospital lethality per genders and ages would allow clarifying aspects regarding morbidity and mortality situations due to CSDs and DM in São José do Rio Preto. In regards to the IHDs, population and hospital mortality rates were found to decrease. Concerning the CVDs, hospital lethality was found to have increased, which signals the need for further studies that also analyze the quality of and access to health care services.

Health education, information on risk factors, measures for educating the population about chronic diseases and complications of SAH and DM, and measures to prevent those diseases must be reinforced, as even with the advancements in public health knowledge, the improvement of those indicators is still weak.

This study pointed towards the need for reorganizing the health care model, by focusing it on primary health care, as those are diseases which are detected by the action of this scope of health care. The proposal reinforces the already-started process of building the Regional Health Care Networks, which are horizontally structured, integrated, solutionoriented, and coordinated by the primary health care administration, through the use of clinical management tools and organization of assistance lines.

\section{References}

1. World Health Organization. Health topics: chronic diseases. Geneva (SWZ): WHO; 2013. [acesso $11 \mathrm{dez}$ 2013]. Disponível em: http://www.who.int/topics/ chronic_diseases/en/

2. Rasella D, Harhay $M O$, Pamponet $M L$, Aquino $R$, Barreto ML. Impact of primary health care on mortality from heart and cerebrovascular diseases in Brazil: a nationwide analysis of longitudinal data. BMJ. 2014;349:g4014.

3. Ford ES, Capewell S. Coronary heart disease mortality among young adults in the U.S. from 1980 through 2002: concealed leveling of mortality rates. J Am Coll Cardiol. 2007;50(22):2128-32. doi: 10.1016/j. jacc.2007.05.056.

4. Schmidt MI, Duncan BB, Azevedo e Silva G, Menezes AM, Monteiro CA, Barreto SM, et al. Chronic noncommunicable diseases in Brazil: burden and current challenges. Lancet. 2011;377(9781):1949-61. doi: 10.1016/S0140-6736(11)60135-9

5. Godoy MF, Lucena JM, Miquelin AR, Paiva FF, Oliveira $\mathrm{DL}$, Augustin JL Jr, et al. Mortalidade por doenças cardiovasculares e níveis socioeconômicos na população de São José do Rio Preto, estado de São Paulo, Brasil. Arq Bras Cardiol. 2007;88(2):200-6. Portugês, Inglês. doi: $10.1590 /$ S0066-782X2007000200011

6. Ministério da Saúde (BR). Secretaria de Vigilância em Saúde. Vigitel Brasil 2012: vigilância de fatores de risco e proteção para doenças crônicas por inquérito telefônico. Brasília (DF): Ministério da Saúde; 2013. 136 p.

7. Instituto Brasileiro de Geografia e Estatistica. Estimativas populacionais [Internet]. 2010. [acesso 12 jul 2014]. Disponível em: http://www.ibge.gov.br/ home/estatistica/populacao/censo2010/default.shtm.

8. Loyola Filho AI, Matos DL, Giatti L, Afradique ME, Peixoto SV, Lima-Costa MF. Causas de internações hospitalares entre idosos brasileiros no âmbito do Sistema Único de Saúde. Epidemiol Serv Saúde. 2004;13(4):229-38. doi: 10.5123/S1679-49742004000400005.

9. Ribeiro AG, Cotta RM, Ribeiro SM. A promoção da saúde e a prevenção integrada dos fatores de risco 
para doenças cardiovasculares. Ciênc Saúde Coletiva [Internet]. 2012 [acesso 11 de z 2013];17(1):7-17. doi: 10.1590/S1413-81232012000100002.

10. Alfradique ME, Bonolo PF, Dourado I, Lima-Costa MF, Macinko J, Mendonça CS, et al. Internações por condições sensíveis à atenção primária: a construção da lista brasileira como ferramenta para medir o desempenho do sistema de saúde (Projeto ICSAP -Brasil). Cad Saúde Pública. 2009;25(6):1337-49. doi: 10.1590/S0102311X2009000600016.

11. Carvalho BG, Souza RKT, Soares DA, Yagi MAN. Doenças cardiovasculares antes e após o programa saúde da família, Londrina, Paraná. Arq Bras Cardiol. 2009;93(6):645-50. Português, Inglês, Espanhol. doi: 10.1590/S0066-782X2009005000003.

12. Gupta A, Wang Y, Spertus JA, Geda M, Lorenze $\mathrm{N}$, Nkonde-Price $\mathrm{C}$, et al. Trends in acute myocardial infarction in young patients and differences by sex and race, 2001 to 2010. J Am Coll Cardiol. 2014;64(4):33745. doi: 10.1016/j.jacc.2014.04.054.

13. Lopez AD, Mathers CD, Ezzati M, Jamison DT, Murray CJ. Global burden of disease and risk factors, 2001: systematic analysis of population health data. Lancet. 2006;367(9524):1747-57. doi: 10.1016/S0140-6736(06)68770-9.

14. Cabral NL. Epidemiologia e impacto da doença cerebrovascular no Brasil e no mundo. Com Ciência [Internet]. 2009. [acesso 12 jul 2014]; 108. Disponível em: http://www.comciencia.br/comciencia/handler.php ?section $=8$ \&edicao $=47$ \&id $=563$

15. Malta DC, Cezáreo AC, Moura L, Moraes Neto OL, Silva JB Junior. A construção da vigilância e prevenção das doenças crônicas não transmissíveis no contexto do Sistema Único de Saúde. Epidemiol Serv Saúde. 2006;15(3):47-65

16. Mansur AP, Favarato D. Mortalidade por doenças cardiovasculares no Brasil e na região metropolitana de São Paulo: atualização 2011. Arq Bras Cardiol. 2012;99(2):75561. doi: 10.1590/S0066-782X2012005000061.

17. Soares GP, Brum JD, Oliveira GMM, Klein CH, Silva NAS. Mortalidade por doenças isquêmicas do coração, cerebrovasculares e causas mal definidas nas regiões do Estado do Rio de Janeiro, 1980-2007. Rev SOCERJ. 2009;22(3):142-50.

18. Bassanesi SL, Azambuja MI, Achutti A. Mortalidade precoce por doenças cardiovasculares e desigualdades sociais em porto alegre: da evidência à ação. Arq Bras Cardiol. 2008;90(6):403-12.

19. Farias NOS. Mortalidade cardiovascular e desigualdades sociais no município de São Paulo,
Brasil, 1996-1998 e 2008-2010. Epidemiol Serv Saúde. 2014;23(1):57-66. doi: 10.5123/S167949742014000100006.

20. Lotufo PA. O escore de risco de Framingham para doenças cardiovasculares. Rev Med. (São Paulo). 2008;87(4):232-7.

21. Allender S, Scarborough P, Peto V, Rayner M, Leal J, Luengo-Fernandez R. European cardiovascular diseases statistics 2008. Oxford (OH): European Heart Network; 2008. $112 \mathrm{p}$.

22. Guidoni CM, Oliveira CMX, Freitas $\mathrm{O}$, Pereira LRL. Assistência ao diabetes no Sistema Único de Saúde: análise do modelo atual. Bras J Pharmac Sci. 2009;45(1):37-48.

23. Malta DC, Silva Jr. JB. Plano de ações estratégicas para o enfrentamento das doenças crônicas não transmissíveis no Brasil e a definição das metas globais para o enfrentamento dessas doenças até 2025: uma revisão. Epidemiol Serv Saude. 2013; 22(1):151-64. doi: $10.5123 /$ S1679-49742014000300002.

24. Barreto MS, Reiners AAO, Marcon SS. Knowledge about hypertension and factors associated with the non-adherence to drug therapy. Rev. Latino-Am. Enfermagem. 2014;22(3):491-98. doi:10.1590/01041169.3447.2442. 